\title{
A Corpus-based Comparative Study of Translator's Style: Focusing on Li Bai's Poems Translated by Rewi Alley and Xu Yuanchong
}

\author{
Feng Tingting, Wang Feng*
}

School of Foreign Studies, Yangtze University, Hubei, 434023, PRC China

*Corresponding Author

Received: 02 Jun 2021; Received in revised form: 01 Jul 2021; Accepted: 08 Jul 2021; Available online: 18 Jul 2021

(C)2021 The Author(s). Published by Infogain Publication. This is an open access article under the CC BY license

(https://creativecommons.org/licenses/by/4.0/).

\begin{abstract}
So far, there are many English translations of Li Bai's poems, but the quality of these translations varies. In the past, most translations were evaluated subjectively. However, the rise of corpus study allows that quantitative approach can be used in translation studies. Based on a self-constructed corpus, this paper conducts a comparative study of translators' styles reflected in two different versions of Li Bai's poems by Rewi Alley and Xu Yuanchong, which is examined at the levels of vocabulary, sentences, discourse. The findings indicate that the two translators have their unique styles. At the word level, Xu Yuanchong uses more flowery words, whereas Rewi Alley's language is plain. At the sentence level, Rewi Alley's version is more formal than Xu Yuanchong's, and Xu Yuanchong 's version strictly corresponds with the original form, while Rewi Alley prefers to be free. At the discourse level, Xu Yuanchong prefers to translate poems with the metrical style, while Rewi Alley's translations are in free verse and easier to understand than Xu's version. A particular effort is further made to interpret the reasons for the different styles of the two translators in the different ideological context. It is hoped that the use of this corpus methodology will contribute to the field of literary translation studies.
\end{abstract}

Keywords - Corpus-based translation studies (CTS), translator's style, Li Bai's poems.

\section{INTRODUCTION}

Li Bai (701-762) is the greatest romantic poet of the Tang Dynasty (618-907) and the best-known Chinese poet in the world. He spent his youth during the reign of Emperor Xuan Zong (or Emperor Ming 713-741) when the Tang Dynasty enjoyed its highest prosperity. With rich forms, a wide range of subjects and unique artistic charm,
Tang poetry shows the highest level of classical Chinese poetry. As one of the famous representatives of the Tang poetry, Li Bai's poetry has great poetic and aesthetic value. The first English collection of Li Bai's poetry translated by Obata was published in 1922. Since then, Li Bai has been known by more and more people around the world. Then many different English versions emerged, but influenced 
by translators' educational background and translation strategies, the quality of these translations varies greatly. Traditionally, studies of poetry translation were mostly subjective, scholars either chose a few typical poems to evaluate the quality, or to analyze the translator's strategies. These studies can certainly provide a deep understanding of several poems, but they lack an overall understanding of the poet and translators. The rise of corpus provides a new way for translation research, and more and more scholars have introduced it into literary translation studies, thus opening up a new model of literary translation studies.

An electronic corpus is a large collection of machine-readable texts that have been gathered according to specific criteria. Corpus-based translation study is essentially a partnership marriage between corpus linguistics and descriptive translation studies (DTS). And it is a transform from the prescriptive approaches prevailing in conventional translation studies to descriptive approaches typical of empirical research (Hu, 2011:3). Conventional translation research attaches more importance to intuition, anecdotal evidence, or a small number of samples, assumes the primacy of the source text and argues that the target text should seek to be as equivalent to the source text as possible. Corpus-based translation studies, however, are primarily concerned with describing the features of translation and translational norms in an attempt to uncover the nature of translation and the interrelationship between translation and social culture, based on statistical analyses of a wealth of corpus data. By using computer-based methods and combining quantitative and qualitative techniques, a descriptive account of translation is provided.

Quantifying style, also called stylometry, has always been one of the oldest traditions in literary studies. However, this well-explored and long-standing scientific methodology has been rarely applied to translations. As a result, most of the past studies dealing with an individual translator's style has largely remained at the level of scholars' impressionistic evaluations or based on intuition and subjective assessment of the translation texts. Recently, the corpus linguistic methodology is introduced to DTS, and more attention has been given to evaluate the translator's style based on corpus data. Translator's style involves the preferences of the translators in vocabulary, sentences, discourse, which influences the readability and target readers' reception. It catches more importance amid the national strategy of Chinese culture "going global".

\section{LITERATURE REVIEW}

Over the last two decades, the use of corpora increased notably in the evolving field of translation studies, with scholars finding new approaches to analyze translated texts. Baker $(1995 ; 1999 ; 2000 ; 2004)$ may be considered as a pioneer in this respect. She and her students, as well as colleagues in the University of Manchester paid much attention to this field, and achieved fruitful achievements. According to Mona Baker, corpus-based translation studies (henceforth CTS) refer to the branch of translation studies that investigate the nature of translation as a product and a process by means of corpora, based on the statistical analysis of the features of translated texts in relation to non-translated texts and the source texts. Since the first translation corpus was constructed, CTS has come to the fore, and a growing number of scholars have been involved in corpus-based translation research. Baker (2000) argues that a study of a translator's style must focus on the manner of expression that is typical of a translator, rather than simply list instances of obvious intervention. It must attempt to capture the translator's characteristic use of language, his or her individual profile of linguistic habits, compared to other translators (Baker 2000: 245).

As CTS originated from the West, Western scholars put more emphasis on the methodology of corpus-based translation studies. A great number of parallel, comparable, and translational corpora were employed to investigate the features of translated texts, translator's style, translation evaluation and interpreting. As for the investigation of the features in translated texts, Pablo Ruano (2017) introduced the comparable corpus in literary translation studies to analyze the speech verbs in four Spanish translations of Hard Times. Sofia Malamatidou (2013) focused on examining how translated Modern Greek popular science articles differ from non-translated ones, which was based on the translated language corpus and the non-translated language corpus. Sara Laviosa (2004) distinguished the differences between CTS and DTS. Some scholars 
endeavored to explore the promising future that a corpus-based approach can possibly be employed to translation evaluation (Bowker, 2001; Hassani, 2011). They argue that a corpus-based translation evaluation can benefit both clients and translators. Lynne Bowker (2001) presented a practical and objective approach to translation evaluation by designing a specially designed Evaluation Corpus, while Ghodrat Hassani (2011) pointed out the Corpus of Contemporary American English (COCA) in a professional setting can be used for evaluation purposes. Some scholars propose that a corpus-based approach can be introduced to other branches of translation studies, such as interpreting. Miriam Shlesinger (1998) explored how to evaluate interpreting based on the corpora of interpreting materials.

As for translator's styles, Chinese scholars explored the translator's styles of different translations through self-constructed corpora, mostly focusing on literature translations. Based on self-constructed corpora, many scholars discovered the textual features and the translator's styles of different genres, such as classics (Zhao Ying, 2015; Liu Zequan \& Yan Jimiao, 2010) and poetry (Liu Haitao \& Fang Yu, 2017; Jiang Shan, 2017; Yang Xiaolin, 2012; Wang Feng \& Liu Xueqin, 2012). For classics, Zhao Ying (2015), taking two translations of the Tao Te Ching as the object, conducted a comparative study to examine the translator's styles in the levels of vocabulary, sentences and discourse; Liu Zequan \& Yan Jimiao (2010) described the use of the reporting verbs headed by Dao and investigated the styles and strategies as employed by the three translators based on a corpus of three English versions of Hong Lou Meng (or Dream of the Red Chamber). As for poetry, Liu Haitao and Fang Yu (2017) conducted a research to investigate the styles variation of the three versions of Stray Birds; Jiang Shan (2017) combined the quantitative and qualitative approaches to analyze the translator's styles from the perspectives of vocabulary, sentences and discourse, which was based the self-constructed corpus of Du Fu's poems translated by $\mathrm{Xu}$ Yuanchong and Rewi Alley; Yang Xiaolin (2012) discussed the translator's styles in four different English versions of poems from $\mathrm{Du} \mathrm{Fu}$; Wang Feng and Liu Xueqin (2012) analyzed the translation styles of an ancient Chinese narrative poem Mulan $\mathrm{Ci}$ with five translators at home and abroad. Up to now, there is no study involving Li Bai's poems based on corpus.

There are many poems written by Li Bai, and most published English translations of Li Bai's poems are selected. This study is based on two translations: the first one, named Li Pai: 200 Selected Poems, is translated by Rewi Alley, and the other, named Selected Poems of Li Bai, is by $\mathrm{Xu}$ Yuanchong; both translations have received praises as well as criticisms. Over the years, both of them have been studied and evaluated carefully, but most of which were based on conventional translation research and subjective judgement. This paper selects 66 poems translated by both Rewi Alley and Xu Yuanchong. Based on a self-constructed corpus of these two versions, the authors aim to better describe the differences in the translation styles of the two famous translators with more convincing analyses. Corpus Word Parser 1.0 was used to parse the words before the research, aiming to get more accurate and convictive data. WordSmith 4.0 was employed to get type/token ratios, mean word length and sentence length, and word frequency. Readability Analyzer 1.0 was employed to calculate the readability and difficulty of the two English translations. A particular effort is further made to interpret the reasons for the different styles of the two translators amid the different ideological context of the translations.

\section{THE ANALYSIS OF TRANSLATOR'S STYLE AT LEVELS OF VOCABULARY, SENTENCES, DISCOURSE}

\subsection{The Analysis of Translator's Style at the Level of Vocabulary}

\subsubsection{TTR}

TTR is one of important factors that can reveal translation styles in corpus-assisted studies (Baker, 2000:248). It refers to the relationship between the total number of running words in a corpus and the number of different words used. Tokens refer to all words included in the text, and types refer to words excluded repetition. Take for example the sentence"I really like translation because I think that translation is really, really interesting."This sentence contains a total of thirteen words; therefore, we could say that it contains thirteen tokens. However, some 
of the words appear more than once in the sentence; therefore, the sentence contains only nine different words, and these are known as types (Bowker, 2001:348). TTR can reveal the lexical complexity of a text to some degree. A high TTR means that the translator uses a wider range of vocabulary whereas a low ratio means that the translator draws on a more restricted set of vocabulary items. But when the size of two texts differs from each other greatly, it is not convincing to compare the TTR of two different texts. Therefore, standard type-token ratio (STTR) is employed here to calculate TTR based on every 1,000 words, which is generally considered to be a much more reliable and objective indicator of lexical complexity of a text.

Table 1 Type/token Ratios of Two English Translations

\begin{tabular}{l|ll}
\hline TEXT & Xu Yuanchong & Rewi Alley \\
\hline Tokens & 5561 & 6277 \\
Types & 1529 & 1585 \\
Type/Token Ratio/ TTR & 27.495 & 23.579 \\
Std.Type/Token Ratio/ STTR & 49.1 & 46.7 \\
\hline
\end{tabular}

Table 1 reveals that STTR of Xu Yuanchong's version is higher than Rewi Alley's, which means that $\mathrm{Xu}$ uses more different words than Rewi Alley. It also shows that the lexical complexity of Rewi Alley's version is lower than Xu Yuanchong's. The tokens of Rewi Alley's version are significantly higher than that in Xu's version, but the types are slightly higher than that of Xu's, which discovers the translation of Rewi Alley is easier to read than that of $\mathrm{Xu}$, as shown in Table 1 . The results are in accordance with Jiang's (2017) research, which discussed the translator's style of $\mathrm{Du}$ Fu's poems translated by $\mathrm{Xu}$
Yuanchong and Rewi Alley.

\subsubsection{Length of Words}

One of the major advantages of corpus-based translation research is that computer technology can do what was impossible to do manually. Word length has always been a neglected part of text research, but it can reflect the word usage and style of the translator. The length of word can reveal the complexity of the translation to some degree. If there are more long words in a text, it means the text is more complicated.

Table 2 Word Length of Two English Translations

\begin{tabular}{l|ll}
\hline TEXT & Xu Yuanchong & Rewi Alley \\
\hline 1-letter words & 312 & 280 \\
2-letter words & 907 & 1260 \\
3-letter words & 1155 & 1430 \\
4-letter words & 1206 & 1426 \\
5-letter words & 858 & 903 \\
6-letter words & 478 & 573 \\
7-letter words & 322 & 414 \\
8-letter words & 184 & 244 \\
9-letter words & 91 & 105 \\
10-letter words & 30 & 54 \\
11-letter words & 10 & 23
\end{tabular}




\begin{tabular}{l|ll} 
12-letter words & 5 & 6 \\
$13-$ letter words & 3 & 4 \\
14-letter words & 0 & 0 \\
Mean word length & 4.1 & 4.1 \\
\hline
\end{tabular}

The statistical results on the length of all words in the two translations are shown in Table 2 , and it can be seen that these two translations are basically consistent in vocabulary. The above analysis shows that there is no big difference between Chinese and Western translators in the use of vocabulary. The results are correspondent to Huo Yuehong's (2010) research.

\subsection{The Analysis of Translator's Style at the Level of Sentence}

\subsubsection{Sentence Length}

TTR and sentence length are two important factors that can reveal (often in part) translation styles in corpus-assisted studies (Baker, 2000:248). The average sentence length refers to the number of words contained in each line of poetry. In the translated text, the length of the sentence is related to the dissemination of original information and additional supplementary information. Translators usually have two options when translating, one is that translators try to keep the original form as much as possible, which means the length of sentences remains the same as the original; the other is that translators ignore the form of the original and pay more attention to the transmission of information: sometimes information is added to make the translation clearer.

Table 3 Sentence Length of Two English Translations

\begin{tabular}{l|ll}
\hline TEXT & Xu Yuanchong & Rewi Alley \\
\hline Number of sentences & 353 & 110 \\
Mean in words & 15.75 & 61.11 \\
Standard deviation & 7.78 & 46.75 \\
\hline
\end{tabular}

It should be noted that there are 110 sentences in all the 66 translated poems of Rewi Alley, since many commas and semicolons are used in his translation. Usually, he translated one poem with one long sentence. It was clearly shown that Xu used nearly 240 more sentences than Rewi Alley. However, the difference in sentence length was even more noticeable. Rewi Alley's translation contains 61.11 words in average in one sentence whereas $\mathrm{Xu}$ has an average of 15.78 words in one sentence, showing a big difference. The results were correspondent to Jiang's (2017) research, which shows that Rewi Alley's translation had 52 words per sentence whereas $\mathrm{Xu}$ used an average of 14 words in one sentence. Xu Yuanchong proposed the "Beauty of form", and he paid much attention to the form of the translation. "Beauty of form" refers to the integral form of the poem, which is determined by the number of lines, arrangement, length, indentation, and structure of poetry. Tang poetry has a typical beauty of form-symmetry. The original poem consists of five or seven characters in each line. As Chinese characters are different from English words, with limited syllables, it is difficult to keep the number of lines, syllables and length corresponding with the original text while the meaning fully expressed. Pursuing the beauty of form, $\mathrm{Xu}$ insisted that $\mathrm{Li}$ Bai's poems should be translated into metrical poems. While influenced by American free verse poetry, Rewi Alley prefers to translate Li Bai's poems into free verse. In the following poem translated by these two translators, the original poem consists of four sentences, and each sentence includes two small sentences with five characters. $\mathrm{Xu}$ translated it into a four-sentence poem, which is strictly consistent with the form of the original 
poem. However, Rewi Alley translated it into one long sentence.

Example 1:

渡荆门送别

李白

渡远荆门外, 来从楚国游。

山随平野尽，江入大荒流。

月下飞天镜, 云生结海楼。

仍怜故乡水, 万里送行舟。

(Original poem)

Farewell beyond the Thorn-Gate Gorge

Leaving Mount Thorn-Gate far away,

My boat pursues its eastward way.

Where mountains end begins the plain;

The river rolls to boundless main.

The moon, celestial mirror, flies;

The clouds like miraged towers rise.

The water that from homeland flows

Will follow me where my boat goes.

(Translated by $\mathrm{Xu}$ Yuanchong)
Farewell at Chingmen

Over the ferry then coming to Chingmen;

travelling in this land of Chu where the hills step down to flat land,

while through the waste the Great River sweeps down;

I look at the wonder of the moon in heaven,

seeming to me like a flying mirror;

stare at the picture a cloud forms of a sea with a tall tower standing up from it;

all beautiful yet none as lovely as my old home;

no matter how far I roam,

ever I wish to take a boat and return again.

(Translated by Rewi Alley)

\subsubsection{Frequency of Words}

Word frequency refers to the frequency of occurrence of different word forms in the text. Word frequency is a basic tool in corpus analysis. A word frequency list allows users to discover how many different words are in the corpus and how often each appears. In translation research, studying word frequency is helpful for studying the styles of the translators. The frequency of word like "the" and "of" can reflect the complexity of phrase and sentence. If the frequency of "the" and "of" is high, the style of the translation is more formal.

Table 4 Word Frequency of Two English Translations

\begin{tabular}{c|ccccc}
\hline \multicolumn{2}{c}{ Xu Yuanchong } & & \multicolumn{3}{c}{ Rewi Alley } \\
\hline Word & Freq. & $\%$ & Word & Freq. & $\% .05$ \\
\hline THE & 377 & 6.87 & THE & 410 & 2.96 \\
TO & 117 & 2.13 & OF & 201 & 2.57 \\
OF & 116 & 2.11 & TO & 174 & 2.06 \\
AND & 99 & 1.8 & AND & 140 & 1.93 \\
I & 98 & 1.79 & A & 131 & 1.84 \\
IN & 93 & 1.7 & I & 125 & 1.36 \\
A & 91 & 1.29 & IN & 92 & 1.17 \\
MY & 64 & 1.17 & WITH & 79 & 1.12
\end{tabular}




\begin{tabular}{c|ccccc} 
WITH & 46 & 0.84 & AT & 68 & 1 \\
IS & 43 & 0.78 & MY & 59 & 0.87 \\
AT & 38 & 0.69 & THAT & 58 & 0.86 \\
FROM & 35 & 0.64 & ON & 56 & 0.83 \\
MOON & 34 & 0.62 & FROM & 54 & 0.8 \\
YOU & 34 & 0.62 & IT & 54 & 0.8 \\
\hline
\end{tabular}

From Table 4 above, we can see the frequency of "the" and "of" in Rewi Alley's version is higher than that of $\mathrm{Xu}$ Yuanchong's version. It means the style of the former is more formal than the latter. The results verified Jiang's (2017) research, which discussed the translator's style of Du Fu's poems translated by Xu Yuanchong and Rewi Alley. It can further reveal that the translator's style remains stable to some degree.

\subsection{The Analysis of Translator's Style at the Level of Discourse}

\subsubsection{Overt Cohesion}

English is a kind of hypotactic language, while
Chinese is paratactic. Hypotaxis refers to the dependent or subordinate construction or relationship of clauses with connectives, while parataxis refers to the arranging of clauses one after the other without connectives showing the relation between them. Hypotaxis in English is inseparable from explicit conjunctions, using overt cohesion to express the logical relations between sentences, such as: "and, but, or, because, if, since, when, that." (Huo, 2010:112) There are no connectives in the original text of Li Bai's poems, and all connections are expressed through the word order or sentence meaning. However, the two translators both added conjunctions to show logical relations.

Table 5 Overt Cohesion of Two English Translations

\begin{tabular}{c|cc}
\hline TEXT & Xu Yuanchong & Rewi Alley \\
\hline And & 99 & 140 \\
but & 18 & 46 \\
or & 5 & 8 \\
because & 1 & 2 \\
if & 10 & 36 \\
since & 4 & 3 \\
when & 30 & 29 \\
that & 9 & 58 \\
Total & 176 & 321 \\
\hline
\end{tabular}

It was clearly shown that Rewi Alley used more overt cohesion than Xu Yuanchong. Rewi Alley added more connectives in his version than $\mathrm{Xu}$ Yuanchong. The contributing factor is that Rewi Alley's translation is free from the limitation of form and try his best to make the translation easy to understand, while $\mathrm{Xu}$ Yuanchong insists to keep accordance with the original form to pursue the beauty of form.

\subsubsection{Reconstruction of Poetic Conceptions}


Table 6 Reconstruction of Poetic Conceptions

\begin{tabular}{c|cc}
\hline TEXT & Xu Yuanchong & Rewi Alley \\
\hline at & 38 & 68 \\
in & 93 & 92 \\
on & 62 & 56 \\
under & 6 & 13 \\
beside & 4 & 19 \\
up & 12 & 34 \\
down & 11 & 12 \\
around & 7 & 17 \\
through & 8 & 318 \\
Total & 241 & 7 \\
\hline
\end{tabular}

The construction of poetic conceptions in poetry is vital to a poem, and it is often reconstructed by positional prepositions in translation. The authors searched the common positional prepositions in the two translations and found that the two translators had great differences in constructing the poetic conceptions. Rewi Alley added many prepositions to help readers easily understand the translation, focusing on constructing the three-dimensional spatialization of the poetic conceptions. However, Xu's translation retains the expressive characteristics of Chinese poetry, superimposed images leaving readers with unlimited imagination.

Example 2:

望庐山瀑布

李白

日照香炉生紫烟,

遥看瀑布挂前川。

飞流直下三千尺,

疑是银河落九天。

(Original poem)

The Waterfall in Mount Lu Viewed from Afar

The sunlit Censer Peak exhales incense-like cloud;

The cataract hangs like upended stream, sounding loud.
Its torrent dashes down three thousand feet from high;

As if the Silver River fell from azure sky.

(Translated by Xu Yuanchong)

Waterfall on Lu Shan

Sun shines on Hsianglu Peak

and then comes a purple

mist; from afar we see

a waterfall, as if it was

a river suspended in mid air

flying three thousand feet,

so did I wonder whether it

was not the Milky Way

descending from heaven.

(Translated by Rewi Alley)

From the example 2 above, we can see that Rewi Alley added many conceptions to reconstruct the three-dimensional spatialization of the poetic conceptions, such as "on Hsianglu Peak, from afar, in mid air".

\subsubsection{Readability}

Readability Analyzer 1.0 was employed to calculate the readability and difficulty of the two English translations. Reading ease and text difficulty are evaluated 
here; the higher text difficulty is, the lower reading ease is. As it was shown in Table 7 , the text difficulty of $\mathrm{Xu}$ Yuanchong's translation is higher than Rewi Alley's, it indicates Rewi Alley's version is easier to understand than $\mathrm{Xu}$ Yuanchong's. And the reading ease of Rewi Alley is higher than $\mathrm{Xu}$, which also shows that Rewi Alley's version is easier to read than $\mathrm{Xu}$ Yuanchong's for readers. The free verse style of Rewi Alley's version may be a contributing factor, because he used words that are plain and easy to understand. This may be related to the translator's purpose and ideology.

Table 7 Readability of Two English Translations

\begin{tabular}{l|ll}
\hline TEXT & Xu Yuanchong & Rewi Alley \\
\hline Reading Ease & 3.60 & 5.70 \\
Text Difficulty & 96.40 & 94.30 \\
\hline
\end{tabular}

Example 3:

\section{春夜洛城闻笛}

李白

谁家玉笛暗飞声,

散入春风满洛城。

此夜曲中闻《折柳》,

何人不起故园情?

(Original poem)

Hearing a Bamboo Flute on a Spring Night in Luoyang

From whose house comes the song of the jade flute unseen?

It fills the town of Luoyang, spread by wind of spring.

Tonight I hear the farewell song of Willows Green.

To whom the tune will not nostalgic feeling bring?

(Translated by $\mathrm{Xu}$ Yuanchong)

Loyang, and Hearing a Flute on a Spring Night

From whose home comes the notes of a flute,

carried by the wind so insistently,

penetrating every corner of Loyang?

Tonight comes the tune of Willow Branches,

which fills my being with longing for my old home!

Who indeed would not feel thus?

(Translated by Rewi Alley)
From the example 3 above, the first line “谁家玉笛暗 飞声" in the original poem means that the sound of the flute can be heard from an unknown house. Xu translated it as "the song of the jade flute unseen". He made "unseen" rhyme with "Green" in the third line, but it leads to difficulties in readers understanding. Moreover, “《折 柳》" is a classical tune played by the flute. It is usually translated as "Plucking Willow", so the purpose of "Green" is only for rhyming. And "bring" was postposed in the last line, aiming to rhyme with "spring", which increased the readers' difficulty in understanding. The rhyme leads to the complexity in meaning. While in Rewi Alley's version, he expresses the poet's feeling with natural and simple words, conveying the spirit of the original poem to the reader in a concise and clear language.

\section{ANALYSIS OF THE DIFFERENT IDEOLOGICAL CONTEXT OF THE TRANSLATORS}

A translator's individual ideology, which may be different from that of others, includes his values, translation thoughts, and translation goals. Translators' style varies with his ideology, nationality, race, beliefs and life experience. Therefore, translator's ideology is crucial in translation studies. It can be found in translator's autobiography and papers, which are related to his translation works. Sometimes, in the preface of his translation works, the purpose of translation may be mentioned. Based on corpus-based research of translator's styles, the authors analyze the linguistic features of the 
target text, the preferences and features in vocabulary, sentence and discourse, the differences between the styles of translators can be unveiled. The comparison of translator's ideology can then be studied to uncover the ideological factors that contribute to these differences.

$\mathrm{Xu}$ Yuanchong was born in 1921 and died in 2021, he was known as a translator and "the only one who can translate poetry into both English and French". He has been engaged in literary translation for more than 60 years, and his translations cover Chinese, English, French and other languages. In the English translation of Chinese ancient poems, he proposed many methods and theories in translating poetry. As a Chinese translator, $\mathrm{Xu}$ Yuanchong regarded it as his duty to disseminate Chinese culture to the world. Xu holds that "faithful" is a crucial standard in poetry translation, and he believes that translators should try their best to express the ideas of the original fully and effectively. He thought that Alley's translations were "broken into run-on lines without rhyme or reason" (Xu Yuanchong, 1991:41). He (1991) pointed that the English translation of Chinese poems can be divided into three types: "metaphrase" or literal translation, "imitation" or adaptation, and"paraphrase" or liberal translation. In the translation of classical Chinese poetry into English, "metaphrase" has developed into free verse translation, "imitation"into adaptation and "paraphrase" into rhymed verse translation. As for "paraphrase", $\mathrm{Xu}$ Yuanchong (2001) put forward the theory that a translated verse should be faithful and beautiful, which requires that the translated work must be as beautiful as the original in sense, in sound, as well as in form. He put his theory into practice in the books he translated from Chinese into English and French.

Rewi Alley (1897-1987) was a prolific Western writer. He dedicated 60 years of his life to the cause of the Communist Party of China, and was a key figure in Chinese history. He went to China in 1927, wrote and translated many works in China, most of which are historic and meaningful. Most of the works that Alley translated during his life were ancient Chinese poems. His translations are neither rhymed nor restricted by metrical rules. They are similar to modern poems and unique in style. By translating directly in his own special style, Rewi Alley has made a clean break with conventions. Using natural, daily spoken language, he faithfully expresses the meaning of the original poem in an implicative and indirect way. In doing so, he not only avoided many strained and complex translations, but also created another way of bringing out Li Bai's style. In the preface, he clearly points out that only the spirit and meaning of the original poem can be brought into English, but the charm of the language is often quite untranslatable. And the poems selected are translated for public reading, which indicates the purpose of the translator is to translate $\mathrm{Li}$ Bai's poems in the simplest language that people can easily understand. In his reflections of translation, he pointed out that the most difficult thing is trying to translate Chinese poetry: the translator should not only preserve the spirit of the original, but also convey the spirit of the original to the reader in a concise and clear way. When translating classical Chinese poetry, the translator must have background information of Chinese history and geography. He believes that if the translator tries to make the text rhyme, or uses obscure language, the translation will become tasteless. The language used by the translator should never be improvised; it should be natural, like water flowing over a round stone.

\section{CONCLUSION}

Based on a self-constructed corpus of 66 poems of $\mathrm{Li}$ Bai translated by Rewi Alley and Xu Yuanchong, this paper conducts a comparative study of translator's styles reflected in the two different versions of these two translators. Both quantitative and qualitative approaches are employed in collecting and analyzing the data. The research makes a multidimensional analysis of the translator's styles, and discovers that the two translators have displayed their unique styles in different ways. At the word level, Xu Yuanchong uses more flowery words, whereas Rewi Alley's language is plain. At the sentence level, Rewi Alley's version is more formal than $\mathrm{Xu}$ Yuanchong's, and Xu Yuanchong strictly corresponds with the original form, while Rewi Alley prefers to be free, aiming to help readers understand the translated poems easily. At the discourse level, $\mathrm{Xu}$ Yuanchong translated poems into metrical style, while Rewi Alley's translations are neither rhymed nor restricted by metrical rules, whereas they are easier to understand than $\mathrm{Xu}$ 's version. 
What's more, a particular effort is further made to interpret the reasons for the different styles of the two translators in the different ideological context. The translation purpose and strategies are contributing factors.

Last but not least, it has to be noted that TTR, sentence and word length and readability can real the translator's style to some degree, but they are far from a complete description of the translation styles of the two English translations. In the present study, we focus on these factors because they are what the corpus tool can provide us at this moment. Corpora are no magic bullets but alleviators as it can only minimize subjectivity in translation evaluation. A corpus should not be seen as a replacement for translation competence and critical judgement, but rather as an aid to help critics make sound and objective evaluations. Thus, a more comprehensive description of the translation styles will entail further efforts.

\section{FUNDING}

The article is supported by the Yangtze University, China.

\section{REFERENCES}

[1] Alley, R. Li Pai 200 Selected Poems [M]. Hong Kong: Joint Publishing Co, 1981.

[2] Alley, R. An Autobiography [M]. Beijing: Foreign Language Press, 2003.

[3] Baker, M. Corpora in Translation Studies: An Overview and Some Suggestions for Future Research [J]. Target, 1995, 7(2):223-243.

[4] Baker, M. The Role of Corpora in Investigating the Linguistic Behavior of Professional Translators [J]. International Journal of Corpus Linguistics, 1999, 4(2):281-298.

[5] Baker, M. Towards a Methodology for Investigating the Style of a Literary Translator [J]. Target, 2000, 12(2):241-266.

[6] Baker, M. A Corpus-based View of Similarity and Difference in Translation [J]. International Journal of Corpus Linguistics, 2004, 9(2):167-193.

[7] Bowker, L. Towards a Methodology for a Corpus-Based Approach to Translation Evaluation [J]. Meta, 2001, 46 (2):
345-364.

[8] Hassani, G. A Corpus-Based Evaluation Approach to Translation Improvement [J]. Meta, 2011, 56 (2), 351-373.

[9] $\mathrm{Hu}, \mathrm{K}$. Introducing Corpus-based Translation Studies[M]. Shanghai: Shanghai Jiaotong University Press, 2011.

[10] Huo, Y. A Corpus-based Comparative Study of Translators' Style [J]. Journal of Dalian University of Technology, 2010, 31 (2): 111-115.

[11] Jiang, S. (2017). "A Corpus Based Study on the Translator's Style in the Two English Version of Du Fu's Poems [J]. Journal of Du Fu Studies, 2017, (3):54-61.

[12] Laviosa, S. Corpus-based Translation Studies: Where Does it Come From? Where is it Going? [J]. Language Matters, 2004, 35(1):6-27.

[13] Liu, Z. \& Yan, J. Choice and Style: On the English Translation of the Reporting Verbs Headed by Dao in Hong Lou Meng [J]. Journal of PLA University of Foreign Languages, 2010, 33 (4): 87-92.

[14] Malamatidou, S. Passive Voice and the Language of Translation: A Comparable Corpus-Based Study of Modern Greek Popular Science Articles [J]. Meta, 2013, 58 (2), 411-429.

[15] Ruano, P. Corpus Methodologies in Literary Translation Studies: An Analysis of Speech Verbs in Four Spanish Translations of Hard Times [J]. Meta, 2017, 62(1), 94-113.

[16] Shlesinger, M. Corpus-based Interpreting Studies as an Offshoot of Corpus-based Translation Studies [J]. Meta, 1998, 43 (4), 486-493.

[17] Wang, F. \& Liu, X. A Corpus-based Comparative Study of Translator's Style: Focusing on Five Versions of The Ballad of Mulan [J]. Journal of Guangxi University for Nationalities. 34 (2): 182-188.

[18] Xu, Y. Selected Poems of Li Pai [M]. Chengdu: Sichuan People's Publishing House, 1987.

[19] Xu, Y. Development of Verse Translation [J]. Journal of Foreign Languages, 1991,75: 35-45.

[20] Xu, Y. On Theories of Rivalry and Advantage [J]. Chinese Translator Journal, 2001, 22: 51-52.

[21] Yang, X. A Corpus - based Stylistic Study of Four English Versions of Bing Che Xing by Du Fu [J]. Foreign Language and Literature Studies, 2012, (4):274-288.

[22] Zhao, Y. A Corpus Based Study on the Translator's Style in the Two English Version of Tao Te Ching [J]. Chinese Translators Journal, 2015, (4): 110-113. 